BULLETIN Bulletin hispanique

HISPANIQUE Université Michel de Montaigne Bordeaux

$116-2 \mid 2014$

Référentialité/autoréférentialité dans le roman espagnol contemporain : bilan et perspectives

\title{
Estrategias referenciales en El nombre de los nuestros (2001) y Carta blanca (2004) de Lorenzo Silva
}

\section{Anne Lenquette}

\section{(2) OpenEdition}

\section{Journals}

Edición electrónica

URL: http://journals.openedition.org/bulletinhispanique/3565

DOI: 10.4000/bulletinhispanique.3565

ISBN: 979-10-300-0156-3

ISSN: 1775-3821

\section{Editor}

Presses universitaires de Bordeaux

\section{Edición impresa}

Fecha de publicación: 1 diciembre 2014

Paginación: 787-803

ISBN: 978-2-86781-963-6

ISSN: 0007-4640

\section{Referencia electrónica}

Anne Lenquette, «Estrategias referenciales en El nombre de los nuestros (2001) y Carta blanca (2004) de Lorenzo Silva », Bulletin hispanique [En línea], 116-2 | 2014, Publicado el 01 diciembre 2017,

consultado el 30 abril 2019. URL : http://journals.openedition.org/bulletinhispanique/3565 ; DOI :

10.4000/bulletinhispanique.3565 


\title{
Estrategias referenciales en El nombre de los nuestros ${ }^{1}(2001)$ y Carta blanca ${ }^{2}$ (2004) de Lorenzo Silva
}

\author{
Anne Lenquette \\ Université de Limoges
}

Cet article étudie les différentes modalités de référence à la guerre du Maroc ainsi que les stratégies d'autoréférence de l'acte narratif à lui-même dans $\mathrm{El}$ nombre de los nuestros et Carta blanca de Lorenzo Silva.

Mots-clés : Lorenzo Silva, (auto)référence, guerre Maroc.

Este artículo estudia tanto las diferentes modalidades de referencia a la guerra de Marruecos como las estrategias de autorreferencia del acto narrativo a si mismo en $\mathrm{El}$ nombre de los nuestros y Carta blanca de Lorenzo Silva.

Palabras claves: Lorenzo Silva, (auto)referencia, guerra de Marruecos.

This article studies the various kinds of reference to the Moroccan war as well as the selfreference strategies of the narrative act in $\mathrm{El}$ nombre de los nuestros and Carta Blanca by Lorenzo Silva.

Keywords: Lorenzo Silva, (self)reference, Moroccan War.

Crente a la amplia literaturización de la guerra civil, otros periodos de la historia de Espańa no han tenido cabida en la llamada novela de la memoria.

1. Lorenzo Silva, El nombre de los nuestros, Barcelona, Destino, 2008 [1 $1^{\mathrm{a}}$ edición : 2001].

2. Lorenzo Silva, Carta blanca, Espasa Calpe, Madrid, 2005 [1ª edición : 2004]. 
ficción literaria ${ }^{3}$, en un momento de crisis y de reivindicación de la memoria histórica dentro de la sociedad española ${ }^{4}$, no deja de llamar la atención ${ }^{5}$. Los dos libros de Lorenzo Silva, asumidos por un narrador omnisciente en tercera persona propenso a la focalización interna, sacan del olvido este conflicto.

El nombre de los nuestros $(N N)$ se sitúa en junio y julio de 1921, unas semanas antes de la derrota de Annual. La narración se mueve entre tres posiciones militares, de modo que el lector se encuentra frente a un relato en que alternan de forma irregular los quince capítulos arraigados en Sidi Dris, Afrau y Talilit ${ }^{6}$. La novela Carta Blanca $(C B)$, publicada posteriormente, constituye a nivel cronológico la continuación de la anterior en la medida en que empieza más o menos donde termina $N N$. Consta de una primera parte fechada en el otońo de 1921, es decir en el momento del envío de tropas de legionarios españoles para « reconquistar » los territorios marroquíes perdidos por los espańoles a raíz del desastre de Annual. Las dos partes siguientes de la novela nos sitúan, mediante sendas elipsis temporales, en la primavera de 1932 y el verano de 1936.

Trataremos, primero, de ver cómo estas novelas introducen de forma subrepticia, a pesar de su índole ficcional, una serie de elementos referenciales a la vez obvios y crípticos. En segundo lugar, estudiaremos el modo de representación del referente histórico (la guerra de Marruecos) en ambas novelas. Por último, mostraremos cómo, más allá de una red referencial

3. El propio Lorenzo Silva, como " nieto de la guerra " (contra Marruecos), subrayó esta injusticia en uno de sus libros de viaje : « [...] aunque casi todos los espańoles de mi generación tienen o han debido tener un abuelo o un tío abuelo que participó en aquella infausta guerra, una espesa capa de silencio y de vergüenza la ha mantenido ajena a la conciencia de mis compatriotas ", in Del Rif al Yebala. Viaje al sueño y la pesadilla de Marruecos, Barcelona, Destino, 2001, p. 1415. Sabido es que existió en los años 30 y 40 una tradición literaria sobre las campañas africanas de las que las novelas El blocao (1928) de José Díaz Fernández, Imán (1930) de Ramón Sender y La forja de un rebelde (1941-44) de Arturo Barea son los máximos exponentes. En los años 90, no se puede hablar stricto sensu de desierto literario. Además de Lorenzo Silva, unos pocos autores como Severiano Gil Ruiz (Prisioneros en el Rif, 1990; El cañón del Gurugú, 1992; La tierra entregada, 1994), Antonio Abad (Quebdani. El cerco de la estirpe, 1997) o Ignacio Martínez Pisón en el terreno de la literatura juvenil (Una guerra africana, 2000) se han esmerado en ficcionalizar la guerra hispano-marroquí.

4. Este momento de interrogación profunda sobre el tema de la memoria se inició a finales de los años 90. En el año 2000, se creó la ARMH (Asociación para la Recuperación de la Memoria Histórica).

5. Huelga decir que la guerra colonial marroquí y la guerra civil poco tienen en común desde un punto de vista estrictamente ideológico y factual (causas, espacio geográfico, duración, medios militares, número de bajas, etc.). Así y todo, para algunos historiadores, los vínculos entre guerra colonial y guerra civil son tales que ésta no se puede entender sin aquélla (cf. Sebastián Balfour, Abrazo mortal. De la guerra colonial a la guerra civil en España y Marruecos (1909-1939), Barcelona, Península, 2002). En todo caso, nada justifica, a nuestro parecer, la omisión de un periodo histórico tan largo (1859-1926) como relevante.

6. Cuatro capítulos se dedican a contar la vida en el campamento de Talilit, cinco la vida en Sidi Dris y seis la vida en Afrau, o sea un total de 15 capítulos. El capítulo 19 y el epílogo están aparte por culpa del salto temporal. 
claramente identificable, el texto no deja de remitir a su propia diégesis y a su quehacer mediante un juego meta e intertextual que encierra una reflexión sobre los mecanismos de la narración y de la creación.

\section{Modalidades De REFERENCia:}

DE LA MIMESIS REFERENCIAL A LA CRIPTOREFERENCIALIDAD

\section{Obviedad del marco referencial}

Lo que llama la atención en $N N$ es la acumulación de elementos paratextuales que subrayan de forma evidente la dimensión referencial de la ficción a pesar del pacto ficcional de lectura. En efecto, la ilustración de la portada, que aparece tanto en la edición de Destino del 2001 como en la edición de bolsillo del 2002, consiste en la foto de unos soldados españoles en Marruecos. Ésta data de 1924 y, como lo indica la contrapágina de los derechos de autores, pertenece al autor. La presencia de una foto corre pareja con un "referente fotográfico " en el sentido que Barthes da a esta expresión, es decir « la cosa necesariamente real colocada delante del objetivo [...] en la Fotografía no puedo negar nunca que la cosa alli estuvo " ${ }^{7}$.

A continuación, la advertencia preliminar de $N N$ nos revela que:

El grueso de la historia que se cuenta en este libro está inspirado en los avatares reales vividos entre junio y julio de 1921 por los soldados españoles, en su mayoría del regimiento de Ceriñola, que defendían las posiciones avanzadas de Sidi Dris, Talilit y Afrau en Marruecos. [...] Ciertos detalles relevantes de la historia proceden de la experiencia y los recuerdos del sargento del Ejército de África Lorenzo Silva Molina ${ }^{8}$ (subrayado mío).

Al filo de la lectura, al lector no le extrañará descubrir que uno de los personajes claves viene emblematizado en la figura del sargento Molina. Dicho de otro modo, el nombre del protagonista es un homónimo parcial del nombre del abuelo de L. Silva, lo que contribuye a no hacer de él una entidad meramente ficticia sino más bien el trasunto ficticio de una persona real.

Además del juego patronímico, el armazón de ambas novelas descansa sobre un referente espacial « real » directamente sacado de la geografía marroquí: las ciudades de Sidi Dris, Afrau y Talilit para $N N$ y las de Zeluán, Segangan y Yebel Harcha para $C B$. Henri Miterrand ha subrayado el papel del marco espacial y su incidencia en la forma en que el lector aprehende el relato:

C'est le lieu qui fonde le récit, parce que l'événement a besoin d'un ubi autant que d'un quid ou d'un quando; c'est le lieu qui donne à la fiction l'apparence de vérité.[...] le nom

7. Roland Barthes, La chambre claire, Euvres complètes (tome V), Paris, Seuil, 2002, p. 783892 [p. 851 citée] : "J'appelle "référent photographique" [...] la chose nécessairement réelle qui a été placée devant l'objectif [...] dans la Photographie, je ne puis jamais nier que la chose a été là ». La traducción al español es mía.

8. Lorenzo Silva, "Advertencia preliminar ", El nombre de los nuestros, p. 7-8. 
du lieu [...] court-circuite la suspicion du lecteur : puisque le lieu est vrai, tout ce qui lui est contigu, associé est vrai'.

$\mathrm{Ni}$ que decir tiene que este proceso de creencia se da de forma aún más evidente cuando el referente encabeza todos los capítulos $(N N)$ o partes $(C B)$ de la novela ${ }^{10}$.

Al fin y al cabo, todos estos elementos (fotografía, advertencia preliminar, homonimia y aprovechamiento narrativo de unos referentes espaciales reales) matizan el carácter puramente « ficcional » de ambas obras y cultivan, de mano, cierta ilusión mimética.

\section{Selección y manipulación del referente espacial}

La elección de los diferentes títulos de capítulos y la puesta en evidencia de los referentes espaciales delatan la presencia de una instancia organizativa (" instance de régie " de Genette). De hecho, ésta se caracteriza por su imparcialidad a la hora de seleccionar y ordenar el material referencial.

En primer lugar, en $N N$, dicha instancia optó por limitar el campo de la acción narrativa a Sidi Dris, Talilit y Afrau, es decir tres espacios diegéticos a escasa distancia de Annual (asociado en las memorias al "desastre " y a la derrota de las tropas españolas). La elección de estos topónimos contrasta con la historia oficial y las recreaciones literarias que han privilegiado hasta hoy escenarios más famosos como los de Annual, Melilla, Monte Arruit o el Barranco del Lobo ${ }^{11}$.

En segundo lugar, el orden de aparición y de reaparición de los diferentes topónimos nada debe al azar. En efecto, los capítulos que se desarrollan en la posición de Sidi Dris ocupan lugares estratégicos en $N N$ (el primer capítulo y cuatro de los seis últimos capítulos: cap. 12, 14, 16 y 18). Por decirlo con las palabras de Henri Miterrand, el polo topográfico de Sidi Dris ocupa en la novela dos polos textuales (principio y final), lo que no deja de subrayar la importancia narrativa de esta ciudad en la construcción del relato. El aprovechamiento narrativo de un topónimo que precisamente no forma parte de la topografía literaria e histórica habitual se puede relacionar con la cartografía personal del propio autor. En el 2002, después de la publicación de su novela $N N$, L. Silva realizó un viaje a Sidi Dris con motivo del rodaje de un documental sobre la acción militar española en el Rif. Este desplazamiento dio pie a unas " anotaciones de viaje ${ }^{12}$ que pusieron claramente de realce los

9. Henri Miterrand, Le discours du roman, PUF écriture, 1980, p. 194.

10. En $C B$, cada una de las tres partes viene encabezada por un referente espacial diferente que corre parejas con un referente temporal. En $N N$, un número y un título encabezan cada capítulo, además de un referente espacial.

11. Rosa Cerarols Ramirez, "Paisaje y memoria: recreaciones literarias de la geografía bélica colonial en Marruecos ", Boletín de la AGE, $\mathrm{n}^{\circ}$ 51, 2009, p. 219-248.

12. Lorenzo Silva, "Un viaje a Sidi Dris", En tierra extraña, en tierra propia. Anotaciones de viaje, La esfera de los libros, Madrid, 2006, p. 177-185. También se puede consultar en línea en 
motivos personales y memorialísticos que habían inducido al autor a llevar a cabo semejante empresa.

En tercer lugar, la elipsis temporal entre los capítulos 1 y 12, ambos ubicados en Sidi Dris, crea una aparente continuidad cronológica, la cual se contrapone a la discontinuidad espacial del relato. Quizás haya que ver en esta difracción espacial una técnica novelesca para cuestionar formalmente cierta concepción unitaria de la realidad. En este sentido, los tres referentes espaciales aludidos conformarían tan sólo parcialmente el puzzle de la realidad de la derrota. El enfoque múltiple de $N N$ se podría interpretar como un intento de acceder a una visión más completa (a falta de ser globalizante) de la guerra y afirmaría la radical heterogeneidad de toda realidad.

\section{Referencia implícita y criptoreferencialidad}

La referencia puede también jugar a ocultarse y apelar voluntaria $y$ conscientemente a la memoria, a la cultura y a la capacidad hermeneútica del lector. Buena muestra de ello viene dada por el personal de la novela.

Si predominan en las dos novelas de Silva unos personajes totalmente imaginarios y ficcionales (un grupo de legionarios en $C B$ y unos oficiales y soldados en $N N$ ), tambien se mueven en la ficción personajes claramente referenciales, de los que la historia ha dejado constancia (por ej., en $N N$, El Jatabi, alias Abd-el-Krim). Ahora bien, a veces, la referencialidad del personaje tiende a manifestarse de modo más o menos implícito. Así es como el coronel Morán evocado en la ficción remite al coronel Morales ${ }^{13}$. El ejemplar sargento Badía del final de la novela no sería más que un trasunto literario del « verdadero sargento Basallo » ${ }^{14}$ que narró su experiencia del cautiverio en Marruecos en sus memorias. Del mismo modo, los dos personajes del capítulo 3 que tan sólo vienen designados por sus nombres de pila (Manolo y Dámaso) y sus funciones respectivas (El comandante general y el Alto Comisario) se refieren a dos personajes castrenses ${ }^{15}$, Manuel Fernández Silvestre ${ }^{16}$ y Dámaso Berenguer,

http://www.lorenzo-silva.com/index_espanol.htm

13. Eduardo-Martín Larequi García, «La guerra de África desde las trincheras: El nombre de los nuestros de Lorenzo Silva», http://www.lorenzo-silva.com [consultado el 07/09/2012], p. 5.

14. Juan José López Barranco, El Rif en armas. La narrativa española sobre la guerra de Marruecos (1859-2005), Madrid, Marenostrum, 2006, p. 248.

15. Eduardo-Martín Larequi García, op. cit., p. 2-3. El propio Silva, en su advertencia al lector, no da los nombres de los generales (Fernández Silvestre y Berenguer) pero señala que esta entrevista histórica no ha tenido lugar en el cañonero Laya $(N N)$ sino en el crucero Princesa.

16. Con respecto a la muerte misteriosa de Fernández Silvestre, Silva recoge en la novela una anécdota de la que se hacen eco los libros de historia. En 1921, a raíz de la desbandada de los españoles, Fernández Silvestre desapareció misteriosamente, sin que se supiera a ciencia cierta si se había suicidado, si había muerto en el combate, si había sido capturado o si se había vuelto loco. Según lo contado en la novela, se le habría visto repitiendo como un loco « Corred, corred, soldaditos, que viene el coco " (p. 243). Ello viene registrado también por Emilio Martín Ferrer, in Atlas ilustrado de las guerras de Marruecos, Madrid, Susaeta ediciones, 2012, p. 143. 
cuya actuación en la guerra de Marruecos quedó plasmada en los libros de historia. Para identificarlos, el lector puede apoyarse en su identidad nominal parcial (el nombre de pila) o paronímica (Badía=Basallo, Morales=Morán). No obstante, en algunos casos, la carga referencial queda puesta en evidencia sin que medie ningún indicio onomástico. Se pasa de lo implícito a lo críptico. Éste es el caso de la descripción que viene a continuación:

Vio salir de su tienda, pizpireto y trotoncillo como siempre, al comandante de la bandera. Un hombrecito ridículo, con un bigotito de raposa y cara de pájaro, que en el fondo de la mirada combinaba de manera pasmosa una dureza inhumana y una ingenuidad casi infantil. Aquel hombre era para Faura todo un síntoma de la anómala realidad en la que vivía inmerso. Un tipejo de quien cualquiera se habría reído fuera del ejército, un alfeñique al que nueve de diez legionarios de la bandera podían apartar de un soplido [...] y al que allí, en cambio, temían todos como si se tratara del mismísimo diablo. Porque el comandante, pese a lo cómico de su continente y a lo simple que podía resultar si uno escuchaba atentamente sus arengas [...] tenía la única pero férrea virtud de no permitir que jamás le temblara el pulso. Ni al ordenar que se impusieran los más severos correctivos a sus hombres, ni al enviarlos bajo el fuego a una muerte casi cierta, ni al exponerse él mismo, armado para la ocasión de una maravillosa inconsciencia o de una confianza obtusa, a que un moro le cortara la carrera [...], y aun en estos momentos era legendaria la capacidad del comandante para evitar que se le moviese un solo músculo de la cara. [...] De más joven, siendo capitán, se había llevado un mal balazo atacando un blocao por la parte de Ceuta. A cuenta de aquello, a decir de los maliciosos [...], el comandante habría venido a sufrir una explicación cruel al tono atiplado de su voz. Lo que sí constaba, y esto también le daba que pensar a Faura sobre el hombre y su carácter, era que había reclamado con insistencia pero sin éxito que se le concediera por aquella acción la Cruz Laureada, la máxima condecoración militar ${ }^{17}(C B$, p. 33-34).

Para empezar, este retrato de uno de los comandantes de la Legión peca a la vez por exceso y defecto de referencia. En efecto, el personaje descrito carece de identidad nominal. Todo el proceso descriptivo consiste, pues, en paliar este " blanco " del narrador. Para ello, éste se vale de una acumulación de datos factuales que van a permitirle al lector ir deduciendo dicha identidad. Gracias a los diferentes datos biográficos proporcionados, el lector se entera de que se trata de un " comandante de bandera ", africanista, al mando de unos legionarios, que se arriesgó la vida en la guerra marroquí unos años antes (" más joven, siendo capitán, se había llevado un mal balazo atacando un blocao ») sin poder obtener por ello la Gran Cruz Laureada. Todos estos biografemas, de sobra conocidos por la historiografía, remiten a la carrera militar de Francisco Franco y al episodio de El Biutz (en 1916) que casi le cuesta la vida ${ }^{18}$. Dejando de lado estos elementos factuales, hay que recalcar el carácter altamente subjetivo y ficcional de un retrato mediatizado por la mirada del legionario Faura, el protagonista de la novela ("vio salir ", " aquel hombre era para Faura ", « le daba que pensar a Faura »). El texto destaca, además, una

17. Lorenzo Silva, Carta Blanca, p. 33-34.

18. Paul Preston, "La forja de un héroe, 1892-1922 ", Franco. "Caudillo de España", Barcelona, Grijalbo Mondadori, 1994, p. 19-57. 
serie de rasgos sicológicos como la capacidad de intimidación (" al que temían todos »), la insensibilidad ( férrea virtud de no permitir jamás que le temblara el pulso ») y la ambición (" había reclamado con insistencia la Cruz Laureada ») que han sido también subrayados por un historiador como Paul Preston. Todo ello se ha de relacionar con la valorización de la dimensión supra-humana del personaje a través de la adjetivación ("inhumana ", " anómala ", « legendaria ») y de la comparación con el "mismísimo diablo ». Se construye así en la mente del lector la "imagen-personaje ${ }^{19}$ de un superhombre inmune a las balas y a la muerte. Es precisamente esta diferencialidad del personaje la que suele caracterizar a los héroes.

Huelga decir que la percepción que el lector tiene no es tal. De hecho, el personaje descrito carece de uno de los atributos principales de los superhombres: el valor. Su actitud ante las balas enemigas se interpreta como un alarde de «maravillosa inconsciencia » o de " confianza obtusa " ya que no como una prueba de valentía. Es más, la suprahumanidad mencionada viene menoscabada por unos procedimientos de desvalorización que invalidan la supuesta heroicidad del personaje. La animalización (" raposa ", " pájaro ", " trotoncillo »), más que participar en el proceso de deshumanización, se asemeja a una técnica de esperpentización. A ello hay que añadir la presencia de unos sufijos con valor despectivo (" hombrecito ", " tipejo ") que dejan entrever la antipatía de Faura, el personaje focalizador, por este seudohéroe. Por último, la insistencia en la voz aguda (" tono atiplado de su voz ») y el uso del adjetivo "pizpireto ", tradicionalmente reservado a la caracterización de la mujer, sugieren de forma insidiosa una feminización del supuesto superhombre. Todo ello redunda en una figura grotesca que mueve a risa no sólo a quien lo mira ("ridículo ", " cualquiera se habría reído ", "lo cómico de su continente ») sino también al lector. En este caso la implicitación de la referencia encierra una dosis evidente de ideología que sirve para transmitirle al lector cierta percepción de Franco ${ }^{20}$.

Tratándose de novelas que abordan el pasado reciente de Espańa, la actitud asumida de reivindicación de la dimensión documental y referencial de una novela se ha de entender como una afirmación de la función memorialística y cognitiva del texto ficcional. Ello no quita que la instancia organizativa del texto manipule estos elementos referenciales con el propósito de enmendar, para bien o para mal, el saber de la historia oficial. Tambien cabe la posibilidad de que el aprovechamiento de la referencia se convierta en un juego en el que se le invita al lector-lectante ${ }^{21}$ a ejercer su capacidad hermeneútica para construir activamente el sentido textual. Por lo tanto, como Jean-Daniel Gollut y Joël Zufferey, abogamos por una definición de la noción de referencia que no se

19. Vincent Jouve, L'effet-personnage dans le roman, Paris, PUF, 1992 [nuestra edición: 2008], p. $40-55$.

20. Encontramos otro retrato criptoreferencial relativo a Millán Astray en $C B$ (p. 35-36).

21. Michel Picard, La lecture comme jeu, Paris, Minuit, 1986, p. 214. El lectante es la parte reflexiva existente en cada lector. 
reduzca a su función " reproductiva " con respecto a la representación de la realidad sino que tome en cuenta su dimensión « interpretativa »:

Nous définissons la référence comme une activité discursive, c'est-à-dire comme l'élaboration dynamique d'une représentation par laquelle un objet est donné à concevoir. En tant qu'activité, la référence met en jeu un processus de coopération entre des agents [...]. Dans cette conception que l'on peut dire constructiviste, la référence conjugue donc les dimensions représentative et communicative du discours $[\ldots]^{22}$.

El análisis de la descripción del comandante de $C B$ pone énfasis en el hecho de que "tout signifie dans un portrait: aucun détail n'est gratuit " ${ }^{23}$. No cabe duda de que esta "supersignificación " ("sursignification ») del personaje novelesco se construye mediante la activación de la doble potencialidad inherente a la noción de « referencia »: representación más o menos fidedigna del referente y participación dinámica y subjetiva del lector en el proceso de representación.

\section{Problematización referencial y postura ideOlógica}

\section{La guerra de Marruecos: un referente problemático}

A pesar de un cuadro referencial más o menos identificable, la novela $N N$ establece una correlación entre el objeto de la referencia (la guerra) y la imposibilidad de acceder a un saber acerca de éste. En una conversación con el sargento Molina, Amador, su amigo y alter ego, recalca en estilo directo la manipulación política y mediática a que dio pábulo la guerra:

[...] Uno compra el periódico y lo leen catorce. Y los catorce tienen opinión [...] Lo que todos tienen en común es una ignorancia enorme de lo que ocurre aquí. Nadie les cuenta esto. Ni siquiera los que vuelven. Los que vuelven se quedan callados, o inventan mentiras aparatosas ( $N N$, p. 70$)$.

El silencio (" callados ", " nadie les cuenta esto ", " ignorancia enorme ") y la mentira (" inventan mentiras aparatosas») subrayan la opacidad de una realidad ocultada tanto por las lagunas como por las máscaras del discurso, tanto por los que están inmersos en ella como por los que la observan desde fuera. En este contexto, los términos "opinión », « inventar " o " contar » sirven esencialmente para hacer hincapié en la falsa transparencia de la palabra como signo referencial.

Esta manipulación del saber acerca de la realidad de la guerra tiene que ver no sólo con el discurso sobre la guerra sino también con el discurso de la guerra en sí. De hecho, se le indica al lector que los soldados de los diferentes frentes reciben unas informaciones poco fidedignas sobre la realidad del conflicto,

22. Jean-Daniel Gollut \& Joël Zufferey, Construire un monde, Lausanne-Paris, Delachaux et Niestlé, 2000, p. 16.

23. Vincent Jouve, op. cit., p. 44. 
según lo evidencia el narrador a través de una focalización interna que le permite penetrar en los pensamientos del sargento Molina:

[...] Molina dejó a un lado sus recuerdos y se concentró en lo que le había contado Haddú. Según las noticias oficiales, lo de Sidi Dris había sido una gran victoria [...]. De la posición ganada y perdida en el mismo día, en cambio, no se informaba mucho. Molina no creía que aquella política, la de dar la espalda a la verdad, sirviera para mucho (NN, p. 30, el subrayado es mío $)^{24}$.

Con esta cita, se ve claramente la dimensión engañosa del discurso oficial y, asimismo el hiato entre el ser y el parecer, entre la realidad y el discurso sobre ésta.

Todo ello pone de realce un engańo generalizado que afecta a las diferentes capas de la sociedad (ejército, población civil, prensa) y que viene reforzado por lo que G. Champeau llama « la variación de los sistemas de referencia que presiden a la interpretación de los signos ", es decir, "las lecturas arbitrarias del referente $»^{25}$. En efecto, en $N N$ late una interrogación sobre el porqué de la guerra que induce al narrador a barajar diferentes interpretaciones, valiéndose de las palabras y los pensamientos de los personajes. En su fuero interno, el anarquista Andreu achaca la guerra de Marruecos a motivos ideológicos: « [...] marchaba en las filas de un ejército burgués, con las armas en la mano para defender el sueño de los burgueses y aquel absurdo capricho burgués de poner la bandera en los riscos resecos de África " $\left(N N\right.$, p. 60 ${ }^{26}$. En cambio, para el ugetista Amador, la guerra de Marruecos echa sus raíces en motivos económicos y así se lo dice a su amigo Molina: «Estamos para quitarles el hierro de las minas » $(N N, \text { p. } 77)^{27}$. Para el alférez Veiga, las razones son más bien castrenses. Sería la ambición y el oportunismo de algunos mandos dentro del ejército lo que explicaría el empeño en la empresa bélica. El lector lo descubre a través de la transcripción de un monólogo: "Habían probado su poderío, habían

24. El sargento duda en otro momento del discurso oficial: «Las informaciones que llegaban a Afrau al respecto eran tan optimistas como pormenorizadas; demasiado para no despertar el recelo de Molina: -Alguien cree que necesitamos buenas noticias » (NN, p. 68).

Además de Molina, el personaje de Andreu revela con motivo de una conversación con Amador sus sospechas: «Pero yo tengo mis dudas sobre si los castigamos a ellos o a los pobres pringados que mandamos [...]. Los jefes [...] dicen que [...]. Pero si hablas con los del convoy del campamento general te dicen que [...]. ¿Y quién tiene razón ?» (NN, p. 112).

25. Geneviève Champeau, "La double tension référentielle et autoréférentielle dans trois romans de Juan Marsé : Si te dicen que caí, Un día volveré et Ronda del Guinardó ", Référence et autoréférence dans le roman espagnol contemporain, Bordeaux, Presses Universitaires Bordeaux 3 , 1994, p. 95-109 [p. 99 citada].

26. Volvemos a encontrar esta visión inspirada en la lucha de las clases en $N N$, p. 176: "Cómo nos han machacado, cabo. Y todo por cuatro hijos de puta que ahora están tan anchos en Madrid".

27. Cf. también $N N$, p. 251: « [entre los presos] Incluso había algunos civiles, empleados de la compañía que explotaba las minas de hierro [...]. Según decían los maliciosos, era por aquellas minas por las que habían ido a hacer aquella guerra ". Conste que uno de los miembros del Sindicato Español del Rif que inició la explotación era Álvaro de Figueroa y Torres, conde de Romanones y presidente del Gobierno entre 1912 y 1918. 
gastado la sangre y el dinero a espuertas [...]. Sólo algunos habían aprovechado para llevarse ascensos y medallas. Y aunque Veiga pertenecía a esta nómina de agraciados, le asqueaba el negocio " (NN, p. 280). En cuanto al protagonista Molina, no puede menos que tomar sus distancias con la coartada cultural tan manoseada por los colonialistas para justificar el afán de conquista:

[...] contempló la vieja ciudadela, donde los europeos habían resistido sobre el lomo de África [...]. Ofreciéndoles la civilización a los moros, como pregonaba rimbombante la propaganda oficial. La civilización que ahora traían las bayonetas de los legionarios. Molina sintió que en su cabeza se acumulaban demasiadas cosas que no encajaban [...] (NN, p. 244-45).

En esta cita, la opacidad del referente viene puesta de manifiesto por este « no encajar ", como si la guerra fuese un puzzle cuyas piezas resultaran falsamente coherentes, como si el sentido último de las cosas le fuera vedado al individuo por un discurso ("la propaganda oficial») destinado a confundirle.

No deja de ser significativo el hecho de que estas múltiples interpretaciones vengan relacionadas con el papel de la palabra: la palabra mediática de la prensa, la palabra oficial del ejército y la palabra propagandística de los colonialistas y de los políticos. Con ello, se subraya el relativismo referencial tanto del signo lingüístico como de la realidad mediatizada por éste. Este relativismo tiene que ver con una heterogeneidad de lo real que ahora viene afirmada no ya formal sino semánticamente.

\section{La representación de la alteridad: ¿̨un necesario maniqueísmo?}

Si se toma en cuenta la índole del referente en ambas novelas (el enfrentamiento bélico), el lector podría pensar que ha de tratarse necesariamente de una novela antagónica ${ }^{28}$, es decir basada en una estructura maníquea en que el soldado español vendría ensalzado y el enemigo marroquí rebajado.

Importa destacar que, tanto en $N N$ como en $C B$, la evocación de la guerra de Marruecos se lleva a cabo desde una doble perspectiva. Por una parte, el

28. Susan Rubin Suleiman, Le roman à thèse ou l'autorité fictive, Paris, PUF, 1983 : «On peut donc définir le contenu d'une histoire à structure antagonique comme un conflit entre deux forces, dont l'une (celle $d u$ héros) est identifiée comme la force du bien, l'autre étant identifiée comme la force du mal» (p. 127). En el caso de las dos novelas que nos ocupan, los protagonistas no se identifican con las fuerzas del Bien. Ocurre incluso lo contrario en $C B$ en que el protagonista Faura está del lado de los que cometen las peores exacciones, sin ninguna justificación. Además, no hay ningún personaje que se ciña a las características del héroe antagónico (Suleiman, p. 131), en particular en lo que respecta a la adhesión a unos valores. Faura está allí para suicidarse y los personajes de $N N$ han sido mandados a Marruecos a su pesar. Muchos dudan de su "derecho " a luchar por esta tierra, critican el sistema injusto del reclutamiento $(C B$, p. 61 o $N N$, p. 30) o las desigualdades sociales inherentes a la guerra $(N N$, p. 70, p. 95-97). Suelen verse a sí mismos como unos "infelices" (NN, p. 79) o unos "desgraciados" (NN, p. 54) y a los mandos como " locos" $(C B$, p. 35$)$. En cuanto a la guerra, viene presentada como una "maquinaria de destrucción » $(C B$, p. 32). 
narrador cuenta y « vive » de forma empática la guerra hecha por los soldados y oficiales españoles desde las diferentes posiciones. De hecho, ello le lleva a adoptar casi siempre el punto de vista espańol, en particular en lo que respecta a la representación de la alteridad encarnada por el Otro. Sin embargo, es interesante notar que, en algunos casos, el narrador desecha el punto de vista omnisciente en provecho de una voz mediatizada por unos personajes que le brindan al lector la perspectiva del enemigo. Trataremos de ver cómo se construye la doble imagen del español y del " moro " y qué delata esta representación desde un punto de vista ideológico.

Recordemos que el título Carta blanca remite, entre otras cosas, a la actitud devastadora de los legionarios españoles en tierra marroquí. Éstos habían interiorizado la consigna de " carta blanca " otorgada por el mando y se sentían autorizados a entregarse a los actos de barbarie más despiadados ${ }^{29}$. De ahí que el narrador no dude en hacer referencia al desprecio y a la superioridad de los europeos con respecto al marroquí: "[Molina] no era como otros militares europeos que sólo veían en los soldados indígenas unos perros útiles para echarlos contra otros perros " (NN, p. 130). El uso reiterado de la palabra

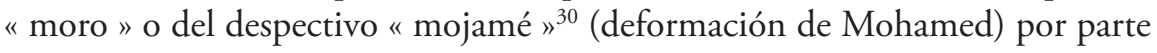
de los soldados españoles remite a dicha actitud.

Estos elementos van conformando en la mente del lector una " leyenda negra » de la realidad de la colonización española en Marruecos. Sin embargo, el narrador también se esfuerza por matizar esta representación de la realidad proponiéndonos a unos personajes más complejos, que no cuadran precisamente con el tipo del colonizador español. En las primeras páginas de $C B$, el lector descubre mediante un fragmento introspectivo a un sargento que tacha a los moros de "demonios rifeños " y de "piojos miserables y sanguinarios " pero que, a pesar de ello, no puede menos que matizar su odio y reconocerle al enemigo el derecho a defender su tierra: « A veces pensaba el sargento Bermejo en eso, en que era su tierra, la de los moros, lo que ellos los extranjeros cristianos, querían arrebatarles. Y, por un momento, entendía que los otros no se aviniesen, entendía que mordieran, y hasta se sentía tentado de respetarlos $[\ldots] »^{31}$ (p. 20). La empatía del sargento con el enemigo se manifiesta a un doble nivel, intelectual y lingüístico: no sólo es capaz de comprender la actitud de sus enemigos (cf. repetición del verbo " entender ") sino que,

29. Cf. " [...] todos entendieron más o menos igual. Podían coger lo que se les antojase, y hacerles a los moros que se encontraran lo que les viniera en gana " $C B$, p. 41$)$.

30. Esta última palabra no consta en los diccionarios académicos. Pertenece, junto con otras palabras derivadas del vocablo " moro " al léxico con que, todavía hoy en día, se tilda despreciativamente a los inmigrantes magrebíes en Espańa.

31. El legionario Faura recalca esta dimensión abusiva de la guerra contra Marruecos: « $\mathrm{Al}$ principio carecía de opinión, pero ahora se daba cuenta de que combatía en una guerra en la que el derecho no estaba de su bando: aquella tierra pertenecía a los moros y ellos no eran nadie para quitársela. Le obligaban a matar a hombres que defendían su casa y a los suyos, y él obedecía " ( $C B$, p. 63). En $N N$, es el personaje de Andreu quien abunda en este sentido: «Pero si se paraba a reflexionar [...] África, en cambio, era de ellos, de los flacos hombres de pardo que los vigilaban desde lo alto $"(N N$, p. 57). 
además, consciente o inconscientemente, adopta su forma de hablar (" ellos los extranjeros cristianos $»^{32}$ ). La presencia de semejante discurso insiste en el derecho del adversario marroquí y, a contrario, sugiere la ilegitimidad de semejante conquista territorial por parte de los españoles.

A veces, el narrador va aún más lejos. Llega a adoptar el punto de vista de los personajes marroquíes como para ofrecer un discurso alternativo con respecto al discurso dominante. En este cambio de enfoque, los españoles vienen descritos como unos " extranjeros enfurecidos e imprevisibles " $(C B$, p. 41), unos " perros cristianos" (NN, p. 255) y los legionarios como " los diablos del Tercio " $(C B$, p. 42$)$ o unos "demonios barbudos" $(C B$, p. 95$)$.

Esta voluntad de otorgarle la palabra narrativa al enemigo supone una búsqueda de equilibrio entre dos discursos ideológicamente opuestos. Ya en su libro de viajes, publicado como $N N$ en el 2001, Lorenzo Silva hacía alarde de su visión especular del español y del marroquí: « Puede que aquella guerra fuera tan terrible y larga precisamente [...] porque [...] nos enfrentamos a nosotros mismos $\|^{33}$ (el subrayado es mío). En este contexto, el posesivo del título $N N$ no remite únicamente, como lo podría esperar el lector, a los muertos espańoles: «El nombre de los nuestros - dijo el sargento [...]. Los nuestros son ellos, los infelices que siempre salen mal parados [...]. Hasta los moros a los que matamos, si lo miras, son los nuestros [...] » (NN, p. 275). Al incluir a los marroquíes en la memoria colectiva española y al manifestar empatía para con todas las víctimas a través del posesivo " nuestro ", la palabra narrativa cobra una dimensión performativa y consigue remodelar el espacio memorialístico de los españoles acerca de la guerra de Marruecos. Se le sugiere al lector una revisión de la historia oficial española y de los discursos dominantes ${ }^{34}$. A cambio se le propone una lectura más integradora y menos maniquea de la guerra de Marruecos.

Dentro de la novelística de L. Silva, las ficciones estudiadas se pueden leer como un díptico en que se equilibran las posturas ideológicas. Si, en $N N$, hace mella en el lector la victimización de los soldados españoles (desde la resistencia desesperada hasta la humillación del cautiverio), en cambio, en $C B$, el lector se estremece ante la victimización de una familia marroquí sometida a la violencia arbitraria de unos legionarios españoles (cap. 10 a 13). El programa narrativo de ambas novelas aboga por un equilibrio que se revela no sólo a nivel textual (empatía con el enemigo) sino también a nivel macrotextual a través de una reversibilidad de los papeles de verdugos y víctimas.

32. El legionario Faura también manifiesta cierta empatía lingüística con el enemigo (cf $C B$, p. $72-73$ y p. 87), como lo indica el uso de una terminología que no puede ser sino la del adversario marroquí.

33. Lorenzo Silva, Del Rif al Yebala..., op. cit., p. 123.

34. Como subraya Juan Goytisolo, en España, este discurso dominante descansa sobre una retórica excluyente y maniquea en que el moro no es nunca el « nuestro » sino el otro: « Desde la invasión árabe, el horizonte de la vida española está dominado, en efecto, por la contraposición entre el cristiano y el moro [...]. Lo ajeno es a la vez musulmán y extranjero. Lo propio es, pues, a la vez cristiano y español [...]. Pero amigo o enemigo, maestro o discípulo, el moro es siempre el otro ", in Crónicas sarracinas, Barcelona, Ruedo Ibérico, 1982, p. 8. 


\section{Metadiscurso E interteXto: DOS ESTRATEgias AUTORREFERENCIALES}

En los últimos decenios del siglo XX, el mundo de la ficción se ha vuelto cada vez más complejo desde la aparición, tanto en Francia como en España, de un relato reflexivo, es decir de un relato que utiliza la diégesis narrativa para proponer una puesta en abismo del proceso de creación, de recepción o de enunciación. No obstante, en el caso de L. Silva, la autorreferencia no se ha de entender como un ejercicio virtuosista o lúdico. Tampoco se afana Lorenzo Silva en presentarnos la génesis de una obra artística o el quehacer de una figura de escritor o de lector. Antes bien, se esmera por subrayar, en un contexto de reivindicación literaria de la memoria, el poder del acto de contar.

Para estudiar las modalidades de referencia de la narración a sí misma en $N N$ y $C B$, partiremos de las tres categorías propuestas por G. Champeau: la autorrepresentación explícita, la autorrepresentación implícita sea con connotación semántica o semiótica ${ }^{35}$. Mediante el análisis de una modalidad narrativa particular, la del cuento oral, más precisamente un cuento tradicional rifeño, veremos qué se nos revela acerca de los mecanismos de producción y recepción de la ficción y acerca del propósito narrativo de $C B$ y $N N$.

\section{La autorreferencia explícita: el acto de contar}

Encontramos en las dos obras un metadiscurso que hace directamente referencia al acto de contar oralmente y a la función recreativa de la palabra. En primer lugar, ésta viene justificada en la novela por las circunstancias en que los personajes se ven involucrados. El campamento o el blocao constituyen una especie de huis clos que legitima a nivel argumental la necesidad para algunos personajes de contar historias. Éste es el caso del cabo Rosales, « un cuentista nato y esforzado " (NN, p. 91). La polisemia de la palabra "cuentista" designa tanto al que sabe contar historias como al que cuenta embustes. Esta ambigüedad semántica viene puesta en evidencia por el relato de un misterioso encuentro entre Rosales y una mujer marroquí. Ni el lector ni el destinatario diegético del relato podrán saber si lo contado remite a una historia real o inventada. Resulta revelador que el propio Silva en su advertencia al lector oscile, no sin cierta fruición, entre realidad e invención. Así es como confiesa sin tapujos que se inspira en " unos avatares reales ", lo cual no le impide recurrir " lisa y llanamente a la invención » a pesar de que el texto no tiene

35. « Ce travail peut prendre la forme d'une autoreprésentation explicite [...], mais se manifester également de manière implicite par le biais de connotations sémantiques (termes autoréférentiels, métaphores etc.) ainsi que sur le mode sémiotique, grâce à la capacité des signifiants eux-mêmes à générer, par leur matérialité formelle et dans un contexte particulier, des effets connotatifs, par-delà les signifiés de langue qui leur sont attachés", Geneviève Champeau, "L'autoreprésentation dans le récit de fiction ", in Annie Bussière-Perrin (coord.), Le roman espagnol actuel. Pratique d'écriture 1975-2000 (II), Montpellier, CERS, 2001, p. 65-98 [p. 66 citada]. 
"un carácter enteramente ficticio $»^{36}$. Desde este punto de vista, la palabra " cuentista " parece aplicarse a la labor híbrida del propio novelista a la hora de escribir su novela.

La importancia concedida a la "verdad " de lo contado se vuelve evidente cuando el narrador evoca, al final de $N N$, los sucesos referidos por los supervivientes ( $N N$, p. 242-243). Todos los verbos relativos a la comunicación oral (" las historias circulaban ", " hablaban de ", " contaban que ", " decían ", " hablaban también de », « referían ») apuntan a la transmisión de unas vivencias basadas en la realidad. Ahora bien, uno no sólo puede contar los hechos sino también su versión de los hechos. Así lo expresa el personaje de Faura en $C B$ : " las historias dejan de estar constituidas por la verdad de los hechos para convertirse ellas mismas en la forma de expresar la inefable verdad de cada uno [...] contarse es la única forma de entender o de hacer como que uno entiende algo » (CB, p. 231).

Dicha cita subraya la triple función cognitiva del acto de contar: difundir un saber, intentar entender el mundo e intentar entenderse. Sin embargo, también recalca la fragilidad del poder cognitivo de la palabra oral. En efecto, siempre cabe la posibilidad de que lo contado no permita llegar al entendimiento (" hacer como que uno entiende algo ") o que se vea deformado por los "rumores" $(N N$, p. 243) o los " chismes" (NN, p. 245).

Por último, contar es recordar los hechos y, por lo tanto, luchar contra el olvido o la ocultación. Ambas novelas insisten en la necesidad de un deber de palabra estrechamente ligado al deber de memoria. De ahí que un Comandante le pida a uno de sus soldados que cuente lo que pasó en Sidi Dris:

- Si sales de aquí, no te olvides de contar a quien quiera oírte que el Alto Comisario tardó más de dos días en autorizar la evacuación.

- Y para qué va a servir eso, mi comandante.

- [...] sólo nos ayudan a salir ahora que estamos medio muertos. No hay que dejar que eso se olvide (NN, p. 199).

Más que un acto lingüístico, contar viene a ser un acto performativo. Contar equivale a brindar un testimonio $y$, sobre todo, a adoptar un comportamiento modélico caracterizado por el rechazo de la historia oficial y de la amnesia histórica.

Los diferentes ejemplos estudiados muestran las diferentes funciones vinculadas con el acto de contar: la función recreativa, cognitiva o memorialística. Todas vienen reivindicadas a través del metadiscurso novelesco pero también puestas en práctica por la novela en sí.

\section{La autorreferencia implícita: el cuento de Munat en $C B$}

De hecho, la reproducción de otro texto dentro de la novela puede servir los designios autorreferenciales de ésta. Es lo que pasa con el cuento de Munat reproducido en bastardillas en el capítulo undécimo de $C B$, a raíz de la violación

36. Lorenzo Silva, El nombre de los nuestros, op. cit., p. 7. 
de una niña rifeña por uno de los legionarios. Al principio del capítulo, el lector va descubriendo el nombre de la nińa (Munat), sus dotes de cuentacuentos y también su cuento favorito. El relato recogido en $C B$ constituye una especie de paréntesis narrativo y viene transcrito en bastardillas, lo que lo diferencia claramente de la diégesis novelesca. Se inspira en un cuento tradicional, titulado "La bestia de las siete cabezas " ${ }^{37}$, en que un nińo, maltratado por su madrastra, decide salir a descubrir el mundo. Al principio de su periplo, el joven mata a un monstruo de siete cabezas y acaba casándose con la princesa a la que éste iba a devorar. El contenido del hipotexto (cuento original) y el del hipertexto (incluido en la novela de L. Silva) resultan similares. Ahora bien, notamos a nivel formal, en la versión de $C B$, una "narrativización » del cuento, o sea que se han borrado la mayoría de los diálogos o intervenciones en estilo directo utilizados por las mujeres cuentacuentos.

Este breve resumen evidencia la relación analógica entre el contenido del cuento y la diégesis de $C B$. Por una parte, el tema del maltrato une a Munat con el joven del cuento. Pero, por otra, Munat se puede también identificar con la princesa. En efecto, existe un paralelismo entre el esquema actancial de la princesa a punto de ser devorada por una bestia de siete cabezas y el de la niña Munat abusada de forma bestial por los siete ${ }^{38}$ legionarios. Esta puesta en abismo ficcional ${ }^{39}$ no funciona de forma totalmente analógica, ya que la princesa del cuento es salvada por el joven, lo que no es el caso de Munat. Sin embargo, el hecho de que Munat piense en el muchacho salvador del cuento precisamente en el momento de su agresión revela el poder catártico de un cuento utilizado como "proyección » en el sentido sicoanalítico de la palabra ${ }^{40}$. Es decir que éste se convierte en un mecanismo de defensa que le permite en cierto modo sobreponerse a una realidad insoportable.

Más allá de su analogía con la diégesis, el cuento de la bestia de las siete cabezas permite hacer hincapié en el acto de narración mediante una diegetización de los papeles de narrador y narratario.

No es casual que el capítulo 11 empiece recordándole al lector que Munat fue receptora de los relatos orales de su madre:

Munat le había escuchado el cuento a su madre, quien a su vez lo había oído antes de la suya. Desde hacía muchos años, tal vez cientos, iba pasando de madres a hijas [...] en el fluir de aquellas voces femeninas que sonaban, llenas de vivacidad e imaginación, en la penumbra escondida de las casas rifeńas ( $C B$, p. 105).

37. Zoubida Boughaba Malecem, Cuentos populares del Rif contados por mujeres cuentacuentos, Madrid, Miraguano ediciones, 2003, p. 41-46.

38. Son siete más uno: el sargento Bermejo encabeza el grupo de los siete legionarios.

39. Lucien Dällenbach, Le récit spéculaire. Essai sur la mise en abyme, Paris, Seuil, 1977, p. 123. Para él, existen dos tipos de puesta en abismo: « [...] l'une fictionnelle, dédoublant le récit dans sa dimension référentielle d'histoire racontée, l'autre textuelle, le réfléchissant sous son aspect littéral d'organisation signifiante".

40. « Término que designa un mecanismo o un proceso de paso del interior al exterior [...]. El sujeto atribuye al otro los pensamientos desagradables que no puede soportar en sí mismo [...] ", in Pierre Fedida, «Proyección », Diccionario de psicoanálisis, Madrid, Alianza editorial, 1988. 
Al ser la destinataria de los relatos orales de su madre, el lector puede llegar a ver en ella una encarnación diegética de la figura del narratario. Sin embargo, Munat se presenta también como el último eslabón de una cadena narrativa de cuentacuentos, unidas entre sí por un espacio común (la casa) y un tiempo inmemorial (« desde hacía muchos años, tal vez cientos»). En este sentido, está condenada a ser una transmisora y, por lo tanto, a ser también portadora del relato de las demás.

Resulta lógico que el texto pase a subrayar sus dotes narrativas, con lo cual la receptora de relatos ajenos se vuelve narradora de sus propios relatos:

Según todas las que la escuchaban [...] aquella muchacha tenía la gracia de las cuentacuentos natas, las que dominaban el arte de hacer que sonara nuevo el relato mil veces repetido, dar vida a los personajes imaginarios y sumergir al auditorio en las emociones de la ficción [...]. De todos los cuentos que solía contar, aquél era su favorito [...] y con el que más convincente resultaba para quien la oía. Al cuento, como a otros, se le conocía por varios títulos, pero el que ella prefería era el de La bestia de las siete cabezas. Éste era un hombre, empezaba diciendo Munat, que tenía dos mujeres [...] ( $C B$, p. 105-106).

En este fragmento, Munat no asume tan sólo el cuento oral de las cuentacuentos sino que, de forma casi subrepticia, sin más transición que el paso de las letras de molde a las bastardillas, pasa a asumir la transcripción ${ }^{41}$ novelesca del cuento oral. Se funden, en cierto modo, dos relatos y dos voces narrativas: el relato oral de la narradora Munat y el relato escrito del narrador heterodiegético de la novela $C B$. La figura del narratario, compuesta en un principio por el círculo de los/las oyentes de Munat, se extiende al círculo de los lectores de la novela.

En última instancia, tras ser sucesivamente productora y receptora de « La bestia de las siete cabezas ", Munat va a desempeñar los dos papeles de forma simultánea, puesto que en el momento de la agresión va a rescatar el cuento de su memoria:

Aquella noche [...] Munat pensó en la bestia de las siete cabezas [...]. Era lástima que a ninguna de las transmisoras anteriores [...] le hubiera dado por adjudicarle al héroe un nombre que ella pudiera pronunciar ahora, aunque fuera para sí, como conjuro contra el temblor que la traspasaba hasta la médula de los huesos ( $C B$, p. 109).

Todas estas variaciones sobre el narrador y el narratario constituyen mutatis mutandis una mimesis de la comunicación literaria que también estriba en el intercambio verbal entre un emisor y un(os) receptor(es).

A otro nivel, llama la atención el que el cuento se vea sometido a una manipulación textual. Si el narrador hace alarde de su oralidad al referirse a la tradición de las cuentacuentos, muy rápidamente, lo convierte en materia

41. Utilizo la palabra "transcripción » en sentido laxo. Para ser más precisa, se trata en realidad de una transcripción en tercer o cuarto grado. Para esta transcripción escrita, la novela se inspira en otra transcripción escrita, la de las cuentacuentos hecha por Zoubida Malecem, la cual procede a su vez de una grabación y de una traducción directa del tarifit al castellano. Por otra parte, lo que encontramos en $C B$ no es una "transcripción » exacta del escrito de Zoubida Malecem. 
escrita mediante un cambio tipográfico (las bastardillas). Este aprovechamiento de lo oral para lo escrito delata e imita a su vez el proceso de elaboración de una obra como NN. A imagen y semejanza de las mujeres cuentacuentos, el propio padre de Silva recogió el relato oral de su padre (el abuelo de L. Silva), de ahí que haya sido calificado de " coautor " del libro (cf. dedicatoria) y de "vehículo de transmisión oral [...] de las historias africanas de su padre " (cf. páginas de agradecimientos). Tanto el relato de las cuentacuentos como el relato familiar quedaron plasmados en un texto escrito. A pesar de la índole diferente de estos relatos orales (el folclore cuentístico en el caso de las cuentacuentos, el testimonio en el caso de $N N$ ), el paso de la oralidad a la escritura supone en ambos casos una transformación de la "memoria comunicativa " (es decir, una memoria que se conserva a través de la transmisión oral) en " memoria cultural » (una memoria que se conserva a través de prácticas u objetos simbólicos) ${ }^{42}$.

Más que revisitar ${ }^{43}$ o resucitar ${ }^{44}$ la tradición de las novelas de tema marroquí, Lorenzo Silva encarna una de las pocas voces literarias que propone y reivindica una más " justa memoria " ${ }^{45}$ dentro de la llamada "novela de la memoria ». No cabe duda de que, para él, ésta pasa tanto por un reconocimiento institucional, académico y popular de nuevos lugares de la memoria (sea los escenarios de la guerra en Marruecos sea la narrativa dedicada a ella) como por la ampliación del concepto de nietos de la guerra hasta hoy reservado exclusivamente a los herederos de las víctimas de la guerra civil. En este contexto, la referencia reflexiva al acto de contar no es una mera postura narcisista de novelista encerrado en su torre de papel. Antes bien, delata una concepción " política ", en el sentido etimológico de la palabra, de la labor novelesca. Contar, por vía escrita u oral, significa recordar los hechos, dejar constancia de ellos y, por lo tanto, participar en el debate público de la Ciudad.

42. Jan Assmann, "Communicative and Cultural Memory ", in Astrid Erll \& Ansgar Nünning (coord.), Cultural Memory Studies: An International and Interdisciplinary Handbook, Berlin-New-York, Walter de Gruyter, 2008, p. 109-125, citado por Elina Liikanen, « Mémoires du conflit, mémoires en conflit : représentations de la guerre civile et du franquisme dans le roman espagnol actuel », Les Langues néo-latines, septembre 2010, n 354, p. 47.

43. Silvia Bermúdez, "El pasado no está muerto: la memoria histórica en la novela de guerra El nombre de los nuestros de Lorenzo Silva », in Ángeles Encinar y Kathleen M. Glenn, La pluralidad narrativa. Escritores españoles contemporáneos (1984-2004), Madrid, Biblioteca Nueva, 2005, p. 163-176.

44. Eduardo-Martín Larequi García, op. cit., p. 1-7.

45. Rose Duroux, "La juste mémoire ?", Cahiers de civilisation espagnole contemporaine, 2/2008, disponible en línea en http://ccec.revues.org [consultado el 07/04/2010]. 